
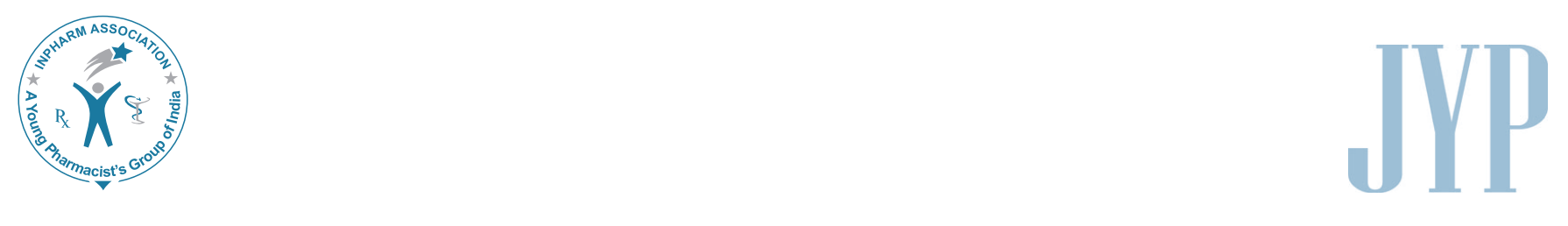

\title{
Seven-star pharmacist concept by World Health Organization
}

"Health is a state of complete physical, mental and social well-being, not merely the absence of disease or infirmity." (WHO, 1946).

The pharmacist is "a person prepared to formulate, dispense, and provide clinical information on drugs or medications to health professionals and patients." A pharmacist is a one of the person in health care team, and he plays a key role in providing quality healthcare and pharmaceutical care to the public. They are experts in medicines and use their clinical expertise, together with formulation, quality control, practical knowledge, to ensure the safe supply and use of medicines by the public. Pharmacists are responsible to ensure the quality of pharmaceuticals/medicines supplied to the patients as per the government policies/regulation, and patient pharmaceutical education including counseling of the patients.

The practice of pharmacy has changed significantly in recent years. While going through history, pharmacy beginning with fossils from natural sources with medicinal properties around 50,000 BC by The Neanderthals. The first prescription (authentic record) was dated back to $3700 \mathrm{BC}$, and earliest histological record for the preparation of medicine comes from Babylonia, circa $2600 \mathrm{BC}$ and this era were priest, pharmacist and physician, all in one. ${ }^{1}$ The first apothecary shop, a private drug store was established in Baghdad late in the $8^{\text {th }}$ century to preserve much of Greco-Roman wisdom and to develop syrups, confections, conserves, distilled waters, and alcoholic liquid with the aid of natural resources. ${ }^{2}$ In the same period, various civilians stated practicing their own system of medicine for treating and preventing diseases. Later, the pharmacist occupied a significant place in the healthcare system by establishing his vital role in the process of drug development, quality control, fundamental research, clinical research and services, patient education and counseling, etc.

The pharmacist's role has been changed from compounder and dispensing chemist to one of "drug therapy manager" and his role expanded from pre/para-clinical to clinical aspects, which includes manufacturing, quality control, drug discovery, regulatory pharmaceuticals, drug dispensing, patient education, patient counseling, hospital/pharmacy administration and community services. ${ }^{3}$

Hepler and Strand coined the term "pharmaceutical care" in the year 1990. Over the next few decades, it gained in significance, not only in pharmacy organizations, but also in every healthcare institution. Pharmaceutical care embodies a patient-centered, outcomes-oriented practice of pharmacy. This practice model promoted the pharmacist as a key member of the healthcare team, with responsibility for the outcomes of medication therapy. Pharmaceutical care delivered by pharmacists seeks to optimize patient outcomes, and is key to the effective, rational and safe use of medicines. ${ }^{4}$

The scope of pharmacy practice now includes patient-centered care with all the cognitive functions of counseling, providing drug information and monitoring drug therapy, as well as technical aspects of pharmaceutical services, including medicines supply management. It is in the additional role of managing drug therapy that pharmacists can now make a vital contribution to patient care. The contribution of pharmacists to health care is based, in most countries, upon a broad understanding of the scientific principles and techniques of the pharmaceutical sciences, and the ability to keep pace throughout their careers with the developments in medicine and pharmacy. Their knowledge and expertise extends to all aspects of preparation, distribution, action and uses of medications. Pharmacist's responsibility has shifted substantially toward the utilization of pharmaceutical knowledge in the rational use of medications by the patient. ${ }^{5}$ To be effective health care team members, pharmacists need skills and attitudes enabling them to assume many different functions. The concept of the "Seven-star pharmacist" was introduced by the World Health Organization (WHO) in March 2014 and covered these roles: Caregiver, decision-maker, communicator, manager, life-long learner, teacher, and leader (Figure 1). ${ }^{6}$ 


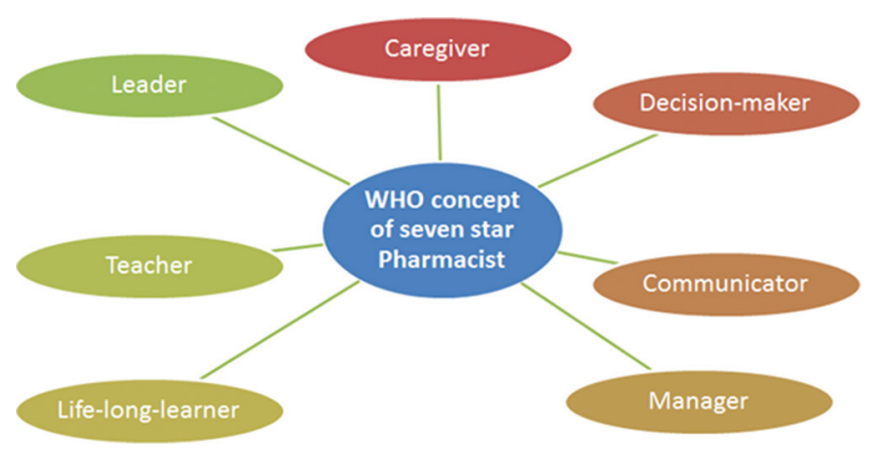

Figure 1: World Health Organization concept of seven-star pharmacist

\section{CAREGIVER}

Pharmacists must provide caring services of the highest quality, and must view their practice as integrated and continuous with those of the health care system and other health professionals.

\section{DECISION-MAKER}

The foundation of the pharmacist's work must revolve around accurate decisions made or taken regarding appropriate, efficacious, safe, and cost-effective use of resources (e.g., personnel, medicines, chemicals, equipment, procedures, and practices). Pharmacists must also play a pivotal role in setting medicines policy both at the local and national levels. The pharmacist must thus, possess the ability to evaluate, synthesize data and information, and decide upon the most appropriate course of action.

\section{COMMUNICATOR}

The pharmacist must provide a link between physicians and patient, and to other health care professionals. He or she should have complete knowledge about all the pharmaceuticals with recent updates and be confident, while communicating with other health care professional and community member. Pharmacists must have effective patient communication skills and it may help him/her to provide better pharmaceutical care to the community by identifying the patient's problem and requirements, ensuring the quality of patient life. Effective communication skills help the practitioners to collect the accurate and comprehensive information form the patient and it will help practitioners to provide successful patientrelated pharmaceutical education to the patient. Strong communication skills will enable a pharmacist to establish the necessary rapport to build a trusting relationship; and to ensure an effective exchange of information necessary for the pharmacist to appreciate patient needs, and for the patient to understand and accept pharmacist recommendations.

\section{MANAGER}

Pharmacists must have the ability to manage the natural and commercial resources which include man power, physical and financial resources. $\mathrm{He} / \mathrm{she}$ must assume greater responsibility for managing the drug label information, ensure the quality of pharmaceuticals and maintain clinical competency and function in patient care activities. Developing and maintaining department policies and procedures, goals, objectives, quality assurance programs, safety, and environmental and infection control standards are key components that aid the pharmacist in evolving as an efficient manager as well.

\section{LIFE-LONG LEARNER}

It is impossible to acquire complete pharmaceutical/ pharmacy education in an institute and professional experience needed to pursue a life-long career as a pharmacist. The concepts of life-long learning must begin, while attending pharmacy school and must be supported throughout the pharmacist's career. Pharmacists regularly update their knowledge and skills in order to keep up with the current trends in issues-related to drug therapy management. The Accreditation Council for Pharmacy Education defines Continuing Professional Development as "the lifelong process of active participation in learning activities that assists individuals in developing and maintaining continuing competence, enhancing their professional practice, and supporting achievement of their career goals." The pharmacist continuous education system must be structured education to support the continuing development to maintain and enhance his competence. ${ }^{7}$ Pharmacists also develop and maintain proficiency in delivering patient-centered care; working as part of interdisciplinary teams; practicing evidence-based medicine and focusing on quality improvement.

\section{TEACHER}

One of the pharmacist's responsibilities is to assist with the education and training of future generations of pharmacists and the general public. The dynamic fashion of pharmacy teaching is not only to import the skill and knowledge to others; it also offers an opportunity for professionals to gain new knowledge and to fine-tune existing skills.

Journal of Young Pharmacists Vol 6 • Issue 2 • Apr-Jun 2014 
The teaching sessions are best conducted in actual practice settings, where the emerging pharmacists can immerse themselves in a real-world pharmacy practice experience. The student pharmacist is also undergo for various exercise to gain knowledge on pharmacy laws and regulatory to improve the professional pharmacists' competencies.

\section{LEADER}

The pharmacist also plays a leadership role in the healthcare system to make decisions, communicate, and manage effectively. A leader is one who can create an idea/vision and motivate others team members to achieve the vision. A leader is a person who continually encourages constructive differences. A leader is mission-driven without being egocentric. Effective pharmacy leaders are experts in demonstrating and creating high-performance pharmacy practices characterized by the high-quality patient care, improved medication safety, and maximum productivity. ${ }^{8}$

Pharmacy is at the heart of the healthcare system, and it plays a very vital role in servicing the essential role in patient healthcare, education, counseling and drug discovery. We pharmacists, must be proud of ourselves, to be an integral part of the healthcare system, and practice our profession in a highly professional manner to fulfill the requirement of WHO to emerge as seven-star pharmacists.

\section{Sam Aaseer Thamby ${ }^{1 *}$, Parasuraman Subramani}

${ }^{1}$ Units of Clinical Pharmacy \& Pharmacy Practice, ${ }^{2}$ Unit of Pharmacology, Faculty of Pharmacy, AIMST University, Semeling, 08100 Bedong, Kedah, Malaysia.
*Address for correspondence: Mr. Sam Aaseer Thamby,

Unit of Clinical Pharmacy \& Pharmacy Practice, AIMST University, Semeling, 08100 Bedong, Kedah, Malaysia.

Email:samthamby@gmail.com

\section{REFERENCES}

1. Pharmacy: A look back at the past and a vision for the future. Pharmacy history. Ch. 1. Available from: http://www.psa.org.au/history-2/chapter1-pharmacy-a-look-back-at-the-past-and-a-vision-for-the-future. [Last accessed on 2013 Apr 27].

2. Bender GA. 'A History of Pharmacy in Pictures' taken from the book "Great Moments in Pharmacy". Available from: http://www.pharmacy. wsu.edu/history/a $\% 20$ history $\% 20$ of $\% 20$ pharmacy $\% 20$ in $\% 20$ pictures. pdf. [Last accessed on 2013 Apr 27].

3. Alabid AH, Ibrahim MI, Hassali MA. Do professional practices among malaysian private healthcare providers differ? A comparative study using simulated patients. J Clin Diagn Res 2013;7:2912-6.

4. Hepler CD, Strand LM. Opportunities and responsibilities in pharmaceutical care. Am J Hosp Pharm 1990;47:533-43.

5. The Role of the Pharmacist in the Health Care System. Available from: http://www.apps.who.int/medicinedocs/en/d/Jh2995e/1.5.html. [Last accessed on 2014 May 01].

6. The Role of the Pharmacist in the Health Care System. Preparing the Future Pharmacist: Curricular Development. Report of the Third WHO Consultative Group on the Role of the Pharmacist, Vancouver, Canada, 2729 August 1997. Geneva: World Health Organization; 1997. Document no. WHO/PHARM/97/599. Available from: http://www.who.int/medicines/. [Last accessed on 2014 May 02].

7. Continuing Professional Development. Available from: http://www.acpeaccredit.org/ceproviders/CPD.asp. [Last accessed on 2014 May 01].

8. 2001 ASHP Leadership Conference on Pharmacy Practice Management Executive Summary. From management to leadership: The building blocks of professionalism. Am J Health Syst Pharm 2002;59:661.

\begin{tabular}{|c|c|}
\hline \multicolumn{2}{|c|}{ Access this article online } \\
\hline Journal Sponsor & \multirow[b]{2}{*}{$\begin{array}{l}\text { Website: } \\
\text { www.jyoungpharm.org }\end{array}$} \\
\hline \multirow{2}{*}{ whw.phcog net } & \\
\hline & $\begin{array}{l}\text { DOI: } \\
\text { 10.5530/jyp.2014.2.1 }\end{array}$ \\
\hline
\end{tabular}

